\title{
COVID-19 critical patients: poor tolerance to hypoxia, insufficient red blood cells, and hypercapnia leading
} to ventilator ineffectiveness?

\author{
Gustavo R. Zubieta-Calleja (MD) ${ }^{1}$, and Natalia Zubieta-DeUrioste (MD) ${ }^{1}$
}

${ }^{1}$ High Altitude Pulmonary and Pathology Institute (IPPA),

Av. Copacabana - Prolongación \# 55,

Estación Av. Del Poeta, Teleférico Celeste

http://altitudeclinic.com,

La Paz, Bolivia.

Corresponding author:

Gustavo Zubieta-Calleja

gzubietajr@gmail.com,

Tel. +59173258026

Disclosures: The authors declare no conflict of interest.

There was no outside funding.

This paper was submitted to Lancet on June 2, 2020. It was not accepted for publication. 


\section{Background}

Critical hypoxia in COVID-19 multifaceted disease is deadly. Ineffective viral treatment and poor understanding of hypoxia continue. COVID-19 was initially considered a SARS "pneumonia" inducing ventilator use. However, $88.1 \%$ died on ventilators(1). A lower high altitude incidence may be due to climate with extreme ultra-violet radiation, and high altitude physiological characteristics such as reduced ACE2 receptor expression(2). Hypoxia simulating High-Altitude Pulmonary Edema (HAPE) was observed. Nevertheless, HAPE reverts within a few days without sequelae. Conversely, Cov-2 induces rapid alveolar-capillary destruction (pneumolysis), resulting in inflammation, immune compromise, and hypoxemia.

Sustained hypoxia normally induces a carotid body upregulation of AT1 receptor expression, increasing response to Angiotensin-II(3). However, ACE2 receptors blocked by CoV-2 as their entry port could decrease Angiotensin-II production. Thereby, carotid body hypoxia sensing could be impaired. This "numbness" interferes with normal pulmonary-cardiovascular compensatory response. Rapid progression to extreme hypoxia in COVID-19 without initial shortness of breath and sudden death could ensue. Following this hypothesis, incipient asymptomatic COVID-19 patients with low pulse oximetry $(<90 \%$ at sea level and $<80 \%$ in $\mathrm{La} \mathrm{Paz}$ at $3,600 \mathrm{~m})$ can be diagnosed before temperature rise. Early treatment could avoid progression. Pulse oximetry in public places is recommended.

COVID-19 hypoxia is similar to acute exposure to Mt.Everest Summit. Initially, the oxygen dissociation curve provides, with ventilation and $\mathrm{PaCO}_{2}$ regulation. As pneumolysis progresses, $\mathrm{PaCO}_{2}$ increases, and with low hemoglobin count, respiratory distress and "gasping" occur. In advanced disease, tolerance to hypoxia rapidly decreases ending life (Fig. 1).

Chronic inflammation processes and underlying conditions even in "healthy" determine an over-reactive capacity of producing an abundance of inflammatory markers. Endothelial ACE2 binding by Cov-2 could lead to platelet site aggregation and thrombus.

La Paz, Bolivia, residents $(3,100-4,100 \mathrm{~m})$ live with perfectly tolerable hypobaric hypoxia levels $\left(\mathrm{SpO}_{2}=90 \%\right.$; normally $98 \%$ at sea level) compensated by increased $\mathrm{Hb}$ (male $=16 \mathrm{~g} / \mathrm{dl}$, and female $=14 \mathrm{~g} / \mathrm{dl}$ ), similar to $\mathrm{SpO}_{2}<90 \%$ (with $\mathrm{FIO}_{2}$ 60\%) in COVID-19 patients using ventilators. Chronic Mountain Sickness patients (polyerythrocythemia=many red blood cells) can survive with Everest-like $\mathrm{PaO}_{2}=30 \mathrm{mmHg}$.

\section{Treatment proposal}

Prompt administration of erythropoietin (Nitric-Oxide stimulator) and/or blood transfusion, oxygen if $\mathrm{SpO} 2<90 \%$, oral rehydration, and acetylsalicylic-acid, increasing the hemoglobin oxygen "pool". At high altitude(IPPA), EPO improves life quality in pulmonary fibrosis or central ventilation alterations. Erythropoietin in one COVID-19 patient resulted favorable (5). Early oxygen administration can avoid further HAPE-type edema due to acute hypoxia.

"Earth open-circuit astronaut-resembling suits" with outside air filtering electric re-breathing systems can enable work return until immunity supremacy.

\section{References}



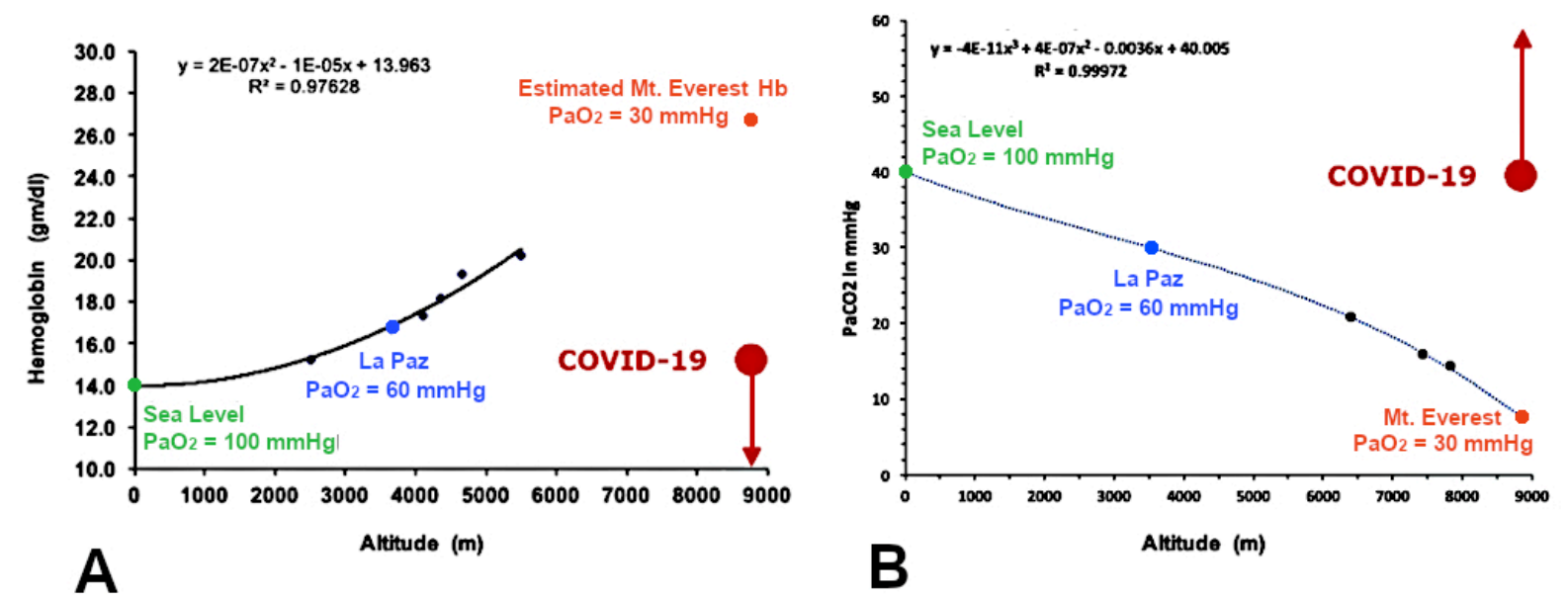

Richardson S, Hirsch JS, Narasimhan M, Crawford JM, McGinn T, Davidson KW, et al. Presenting Characteristics, Comorbidities, and Outcomes Among 5700 Patients Hospitalized With COVID-19 in the New York City Area. Jama. 2020;323(20):2052.

2. Arias-Reyes C, Zubieta-DeUrioste N, Poma-Machicao L, Aliaga-Raduan F, Carvajal-Rodriguez F, Dutschmann M, et al. Does the pathogenesis of SARS-CoV-2 virus decrease at high-altitude? Respiratory Physiology \& Neurobiology. 2020;277:103443.

3. $\quad$ Fung M. The role of local renin-angiotensin system in arterial chemoreceptors in sleep-breathing disorders. Frontiers in Physiology.2014;5:336. Epub 2014/09/25

4. Zubieta-Calleja G, Ardaya G, Zubieta-DeUrioste N, Paulev PE, Zubieta-Castillo G. Tolerance to Hypoxia. Fiziologichnyi Zhurnal. 2013;59(4):65-75 https://zunivnet/pub/TolerancetoHypoxiaFiziolpdf 2012.

5. Hadadi A, Mortezazadeh M, Kolahdouzan K, Alavian G. Does recombinant human Erythropoietin administration in critically ill COVID-19 patients have miraculous therapeutic effects? Journal of medical virology. 2020. Epub 2020/04/10. doi: 10.1002/jmv.25839. PubMed PMID: 32270515.

Fig. 1. Tolerance to Hypoxia $=\left(\mathrm{Hb} / \mathrm{PaCO}_{2}\right) \times$ 3.01. A)Hemoglobin-Altitude, $\left.\mathrm{B}\right) \mathrm{PaCO}_{2}$-Altitude. Red arrows: COVID-19, at sea level, simulating Mt.Everest extreme hypoxia, under opposite conditions to expected optimal lifesustaining physiology(4). 